Is Direct Microwave Heating well adapted for Sintering of Ceramics?

Tristan Garnault ${ }^{\mathrm{a}, \mathrm{b}^{*}}$, Didier Bouvard ${ }^{\mathrm{a}}$, Jean-Marc Chaix ${ }^{\mathrm{a}}$, Christelle Harnois $^{\mathrm{b}}$, Sylvain Marinel ${ }^{\mathrm{b}}$

${ }^{a}$ Univ. Grenoble Alpes, CNRS, Grenoble INP, SIMAP, 38000 Grenoble, France

${ }^{b}$ Normandie Univ, ENSICAEN, UNICAEN, CNRS, CRISMAT, 14000 Caen, France

*corresponding author 


\section{Is Direct Microwave Heating well adapted for Sintering of Ceramics?}

\section{Abstract}

The feasibility of ceramic sintering by direct microwave heating has been studied. This study is based on both experimental tests and numerical simulations, coupling electromagnetic, thermal and densification, of the sintering of alumina and yttria doped zirconia samples in a $2.45 \mathrm{GHz}$ resonant cavity with automatic thermal monitoring. Alumina and yttria doped zirconia are widely distributed materials with different microwave field behaviours (transparent and absorbent, respectively), representative of most ceramic materials. The influence of the insulating material was discussed by considering different sintering cell designs. The very low coupling capacity of alumina makes its direct heating very difficult. It is therefore necessary to apply a strong electric field to heat it. This promotes the absorption of microwave energy by other elements such as the insulation material leading to heating instabilities and degradation of the insulation cell. In the case of zirconia, its properties change very quickly with temperature. It goes from a low absorbing behaviour at low temperature, to a very absorbing behaviour to finally become reflective at the end of the sintering process. The consequences of this rapid evolution of its properties are (i) a very difficult control of its direct heating, (ii) a propensity to form damaging hot spots and (iii) the inability to reach high temperatures without forming plasma. Thus, this study shows that direct microwave heating is not a suitable heating method for obtaining reliable and homogeneous sintering of ceramics and that susceptor-assisted heating should be preferred.

Keywords: microwave sintering; direct heating; alumina; yttria doped zirconia, single-mode cavity

\section{Introduction}

The interest of microwaves for fast and low-energy sintering of ceramic powders has been investigated for decades [1]. A literature survey shows that microwave heating of ceramics has been more successful when the heating was assisted by a susceptor [2][4]. A susceptor is a component made of a material, such as silicon carbide, that strongly couples with microwaves and transmits heat to the sintering part, mainly by radiation. For example, Curto et al. (2020) [5] used a ring of $\mathrm{SiC}$ as a susceptor to sinter alumina parts 
shaped by compaction or stereolithography, with a heating rate of the order of $250^{\circ} \mathrm{C} / \mathrm{min}$. They obtained materials with mechanical properties comparable to those measured on conventionally sintered materials, with $75 \%$ shorter total heating cycle. On their side, Monaco et al. (2015) [6] succeeded in sintering yttria-doped zirconia samples up to $98 \%$ relative density in only 6 min. Again, a SiC susceptor with a crucible-type geometry was used. The choice of these authors for an assisted heating method was motivated by the fact that widespread ceramics such as alumina and zirconia do not couple with microwaves in a stable and efficiently way. Moreover, the way those ceramics interact with microwaves can strongly vary with temperature, which makes it difficult the control of microwave heating.

Nevertheless, some papers have already reported the microwave sintering of alumina and zirconia without any susceptor. Alumina is a low-loss dielectric material which couples very weakly with microwaves, especially at room temperature. This oxide is generally considered to be "microwave transparent" [7], [8]. However, its coupling ability improves with increasing temperature [9] and the direct microwave heating of alumina could be possible if a very high electrical field is applied. Based on that idea, Croquesel et al. designed a microwave equipment combining an impedance adapter and a resonant single-mode cavity [10], allowing direct sintering of alumina [11] through the application of a high electrical field. Cheng et al. (2002) [12] succeeded in producing transparent $\mathrm{MgO}$ doped alumina by microwave sintering in hydrogen atmosphere. These authors were able to apply a heating rate of $100^{\circ} \mathrm{C} / \mathrm{min}$ up to $1880^{\circ} \mathrm{C}$. No reference to any susceptor was mentioned. Nevertheless, the experimental details described in the paper do not allow to be certain that the authors really worked in a direct configuration. Mizuno et al. (2004) [13] proposed a different approach to microwave sintering of alumina by designing an "isothermal barrier", i.e., a thermal insulating box composed of two layers. The thin inner layer was made of a material with microwave absorption properties similar to the ones of the sample, and the thick outer layer was made of a material with both low heat conductivity and low microwave absorption. The objective was to ensure a homogeneous heating of the sample by limiting its thermal losses from its surface thanks to the simultaneous heating of the sample and of the inner layer of the barrier. This method assumes that the alumina can be heated by direct irradiation of both the sample and the inner layer. Nevertheless, it is ultimately comparable to a hybrid heating mode resulting from the combined interaction of the sample and the susceptor with the electric field. 
Concerning zirconia-based materials, and especially yttria doped zirconia, direct heating seems to be easier to achieve. Even though zirconia weakly couples with microwaves at room temperature, its ability to absorb microwave radiation strongly increases with increasing temperature [7], [9]. This is due to the ionic conductivity of zirconia which strongly increases with increasing temperature [14]. It has also been reported that the sudden increase of the coupling capacity of this material with temperature may lead to difficulties in controlling the heating, as thermal runaway may occur. In a previous work Goldstein et al. (1999) [15] were able to fully sinter parts made of 5.17 wt.\% yttria-stabilised zirconia without damage. They actually avoided thermal runaway by finely adjusting the forward power during the test but they were not able to follow a rigorously constant heating rate, even for a relatively low value such as $10^{\circ} \mathrm{C} / \mathrm{min}$. Otherwise they observed an acceleration of the heating rate at high temperature, which was difficult to control. The authors also carried out rapid sintering cycles (of the order of $100^{\circ} \mathrm{C} / \mathrm{min}$ ) conducting to cracks or defects in their samples. Another strategy was proposed by Charmond et al. (2010) [16] who managed to apply a constant heating rate by adjusting the electric field intensity by manually tuning the shortcircuit plunger of the single mode cavity. These authors were able to sinter $2 \%$ mol yttria doped zirconia without any susceptor, applying a heating rate of $25^{\circ} \mathrm{C} / \mathrm{min}$. However, they observed a microstructural heterogeneity in the sintered parts attributed to poor thermal insulation.

The lack of further development of direct microwave heating of ceramic is regrettable since direct heating is, by principle, the best way to benefit from all the advantages of microwaves: low energy consumption, short processing time with rapid heating process, [17], [18] and possible specific effects of the electromagnetic field on the diffusion/microstructural changes [19].

This paper thus questions the issue of direct microwave heating of ceramic powders as a sintering process. This issue is addressed by coupling experiments performed on alumina and zirconia and multiphysics numerical simulations. The experimental setup will be first presented with an emphasis on the insulating cell containing the sintering sample. The finite element simulation coupling electromagnetic wave propagation, heat transfer and sample deformation will also be described. The direct heating capacity of alumina will thus be studied with both experimental and numerical 
tools and the major role of the cell design will be pointed out. The same investigation will be carried out with yttria doped zirconia.

\section{Materials}

The powders used in this study are $\alpha$-alumina WA15 powder with a theoretical density of $3.98 \mathrm{~g} . \mathrm{cm}^{-3}$ and a specific surface area of $23,6 \mathrm{~m}^{2} \cdot \mathrm{g}^{-1}$, and $3 \mathrm{~mol} \%$ yttria-doped zirconia BSZ3Y powder with a theoretical density of $6.1 \mathrm{~g} . \mathrm{cm}^{-3}$ and a specific surface area of $14.1 \mathrm{~m}^{2} \cdot \mathrm{g}^{-1}$, both provided by Baikowski, France. Cylindrical compacts with 8 $\mathrm{mm}$ diameter and $8 \mathrm{~mm}$ height were obtained by uniaxial compression in a floating die. In order to get a relative density between 46 and $49 \%$, pressures of the order of $80 \mathrm{MPa}$ and $250 \mathrm{MPa}$ were applied to alumina and zirconia powders, respectively.

\section{Microwave heating}

The capacity of a material to convert microwaves into heat is proportional to the imaginary part $\epsilon^{\prime \prime}$ of its dielectric permittivity $\epsilon_{r}^{*}=\epsilon^{\prime}-i \epsilon^{\prime \prime}$, according to [20] :

$$
Q_{e}=\frac{P_{d}}{V}=2 \pi f \epsilon^{\prime \prime} E^{2}
$$

where $Q_{e}\left(W \cdot m^{-3}\right)$ is the power density converted into heat, $P_{d}(W)$ the dissipated power, $V\left(\mathrm{~m}^{-3}\right)$ the volume of the absorbent material, $f(\mathrm{~Hz})$ the microwave frequency and $E$ the electric field strength inside the material. $\epsilon^{\prime \prime}$ takes into account both polarisation losses, i.e., the dissipation of energy due to the movement of dipoles (intrinsic or induced), and losses due to the Joule effect. A material which strongly absorbs microwave is said to be a good coupling material.

\subsection{Microwave device}

The microwave equipment comprises a single-mode resonant cavity (or applicator), i.e., a section of waveguide delimited by an iris and a short-circuit plunger. The waveguide is rectangular, with a cross section of $86.36 \times 43.8 \mathrm{~mm}^{2}$ (WR340), so that it transmits the fundamental mode $\mathrm{TE}_{10}$. The overall system shown in Figure 1a includes: (i) a $2.45 \mathrm{GHz}$ generator (GMP20KSM, SAIREM), delivering a forward power $\left(\mathrm{P}_{\mathrm{f}}\right)$ up to $2 \mathrm{~kW}$, (ii) an isolator, protecting the generator from the reflected power $\left(\mathrm{P}_{\mathrm{r}}\right)$, (iii) a manual 
three-stub impedance adaptor (AI3SM, SAIREM), improving the transfer of microwaves from the waveguide to the applicator, (iv) an iris holder, allowing the adjustment of the iris position, (v) the resonant cavity, in which the insulating cell and the heated sample are located and (vi) a motorized short circuit plunger holder (PCC MOT SBS/EB, SAIREM). In this study, the cavity is tuned to excite $\mathrm{TE}_{105}$ mode, i.e., five electric field maxima are generated, as represented in Figure $1 \mathrm{~b}$. The samples were placed $\sim 217 \mathrm{~mm}$ from the iris, whose position is fixed during the test. On the contrary, the position of the short-circuit plunger can be tuned during the test.

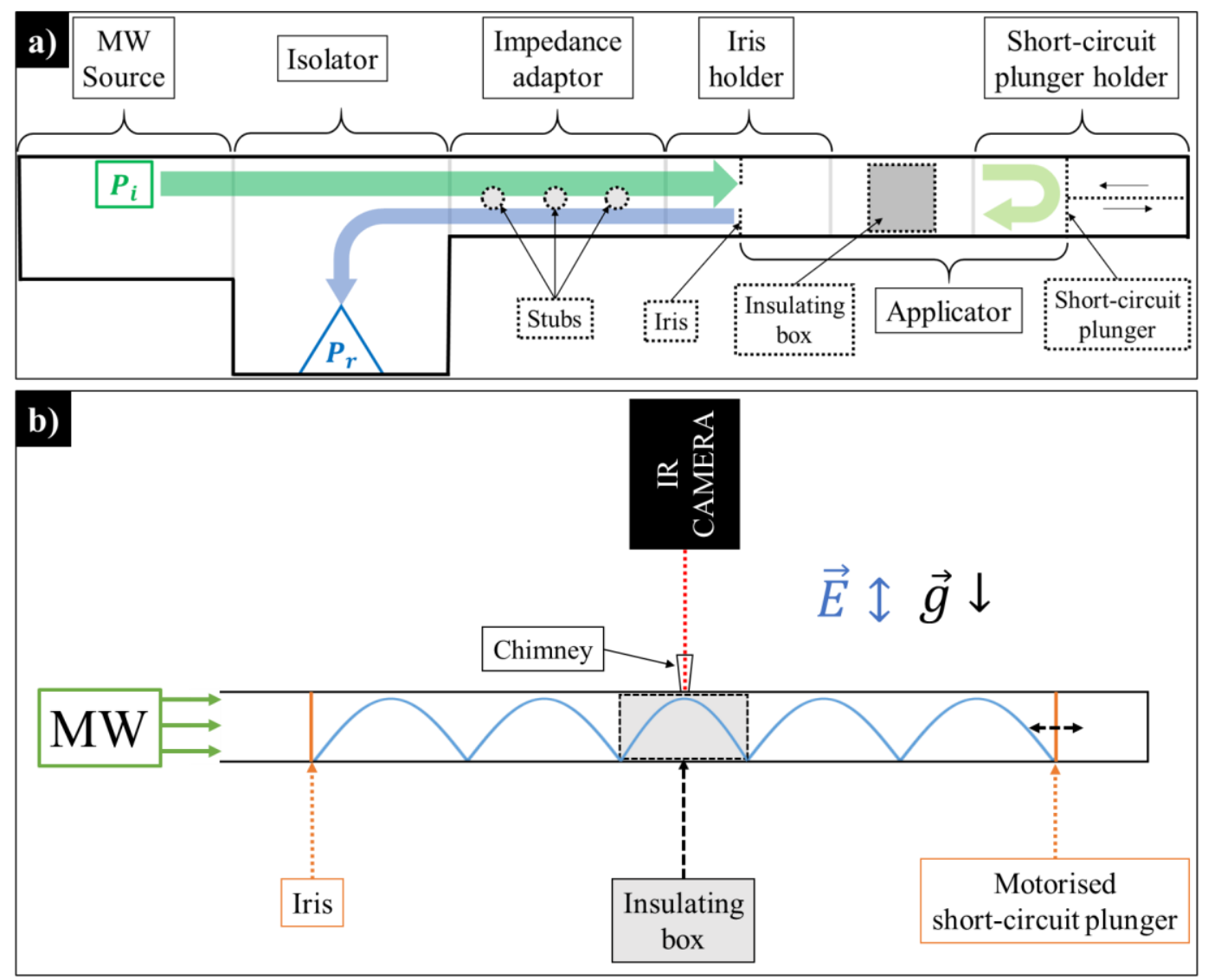

Figure 1. Single mode microwave sintering set-up: a) description of the components $b$ ) position of the insulation cell in the applicator in $T E_{105}$ mode

\subsection{Regulation}

At constant forward power, the intensity of the electric field in the cavity can be modulated by adjusting the applicator length, with a maximum value when the resonance condition is reached. In this way, it is possible to adjust the power dissipated in the sample 
in order to control its heating (Equation 1). Figure 2 schematizes the automatic control method used in this study. The short-circuit plunger (SCP) position is automatically tuned thanks to a PID module calculation based on the difference between the set point temperature $\left(T_{\text {set }}\right)$ and the actual measured temperature $\left(T_{m e a}\right)$. The short-circuit plunger is initially placed away from the resonance condition in such a way that its forward movement, i.e., a decrease in the applicator length, brings it closer to resonance, increasing the intensity of the electric field inside the cavity.

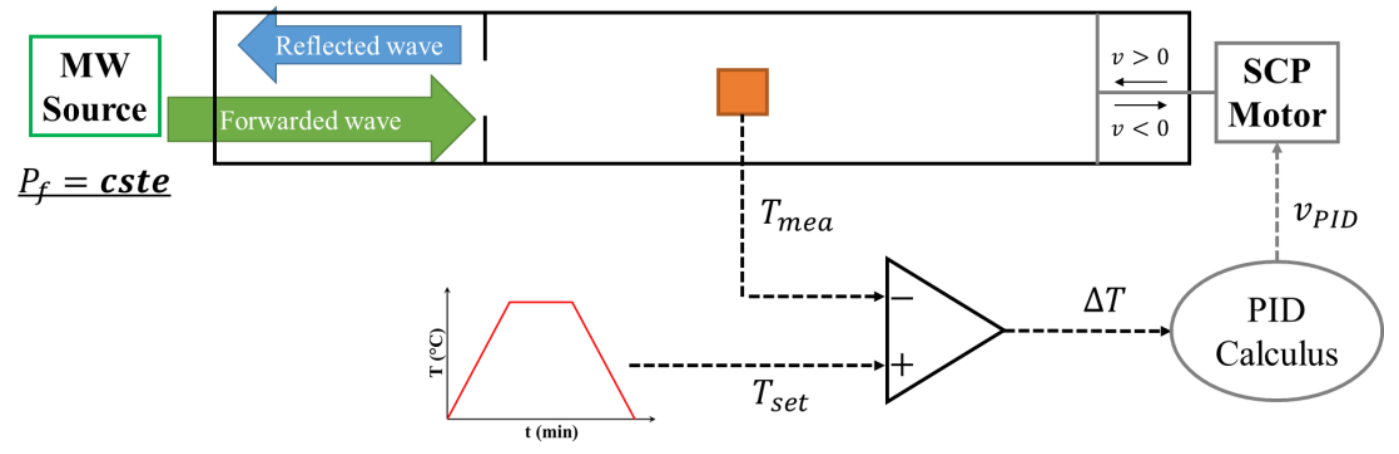

Figure 2. Block function diagram of the automated microwave temperature regulation with resonance tuning by applicator length adaptation

The total dissipated electromagnetic power $\left(P_{d}\right)$ can be calculated as the difference between the forwarded power and the reflected power:

$$
P_{d}=P_{f}-P_{r}
$$

This power is, as a first approximation, the power dissipated by the material and its surrounding thermal insulation box. It should be kept in mind that $P_{d}$ is proportional to the square of the applied electrical field (equation 1). Therefore, tuning the electromagnetic power into the cavity is equivalent to tuning the applied electrical field.

\subsection{Temperature measurement}

An open conic chimney allowed the temperature to be measured by radiation thermometry (Figure 1b). Its dimensions, $9 \mathrm{~mm}$ smaller diameter, $12 \mathrm{~mm}$ larger diameter and $50 \mathrm{~mm}$ height, have been chosen so as to disturb the electric field in the cavity as little as possible. The temperature of the sample was evaluated by a thermal camera (A665sc, FLIR) with a temperature range from -20 to $2000^{\circ} \mathrm{C}$. The temperature used for 
the PID calculations ( $T_{\text {mea }}$ ) was the maximum temperature measured in the upper circular surface of the cylindrical samples. Considering the wavelength range of the thermal camera $(7.5-14 \mu \mathrm{m})$ and the intrinsic emissivity of the heated materials in this wavelength range [21], [22], an emissivity of 0.95 was used for temperature measurement.

\subsection{Insulating cells}

Three isolating cell designs compared in this study are presented in

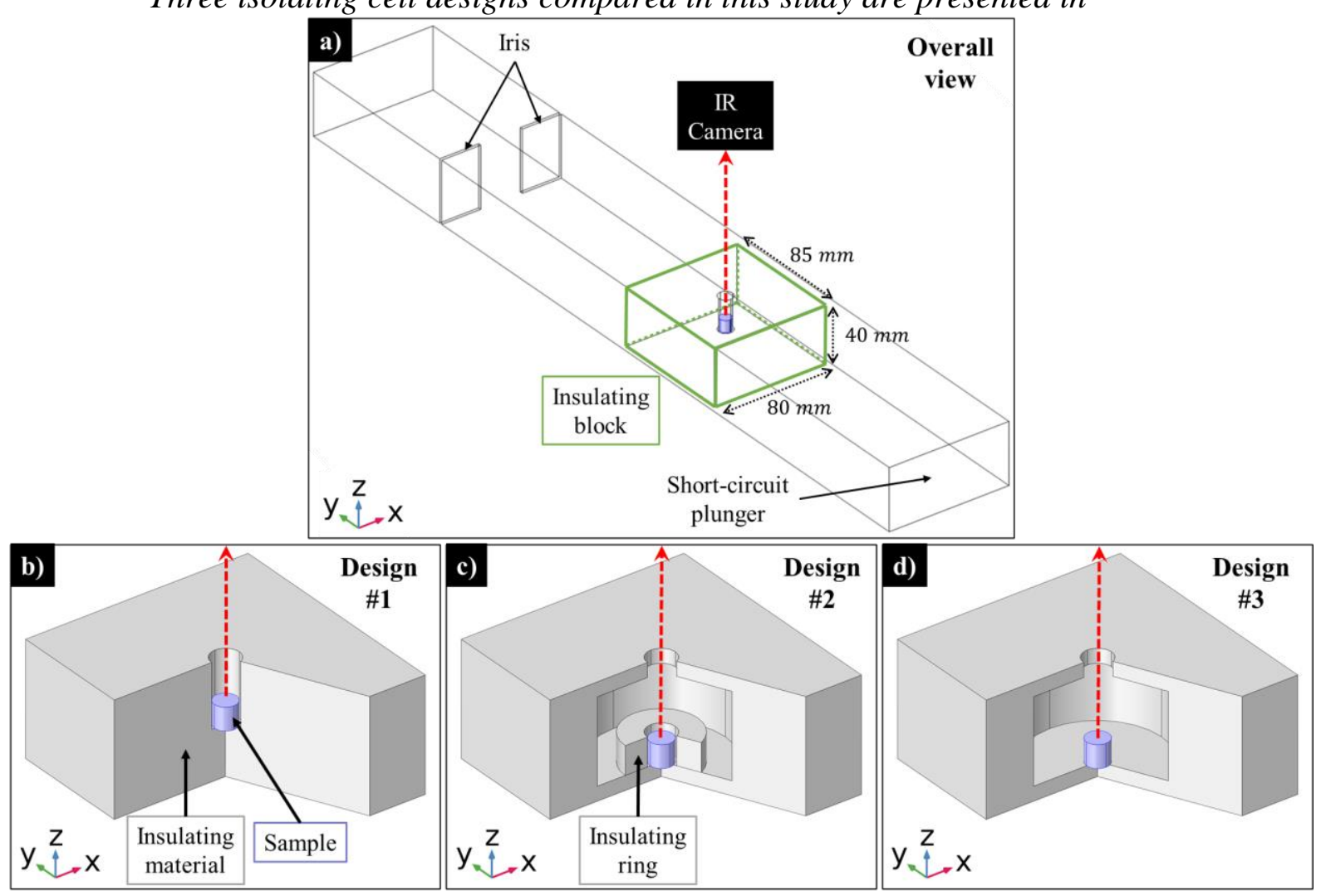

Figure 3. They were all made of the same material, Altraform ${ }^{\circledR}$ KVS 184/400 (RATH), a low-density aluminosilicate (78 wt. $\% \mathrm{Al}_{2} \mathrm{O}_{3} ; 22 \mathrm{wt} \% \mathrm{SiO}_{2} ; 400 \mathrm{~kg} / \mathrm{m}^{3}$ ), which is supposed to couple weakly with microwaves [23]. According to the supplier, the maximum operating temperature of this material is $1800^{\circ} \mathrm{C}$.

- Design \#1 consisted of a block of insulation in which a hole of approximately 9$10 \mathrm{~mm}$ diameter and $27 \mathrm{~mm}$ height containing the sample was drilled. The purpose of this configuration was to ensure the most effective thermal insulation of the sample (except for the upper surface, open to allow temperature measurement).

- Design \#2 reduced the amount of insulating material in the region where the electric field is maximal. A hollowed-out part of $46 \mathrm{~mm}$ diameter and $30 \mathrm{~mm}$ height has been machined in the centre of the cell. The thickness of the insulation 
beneath the sample was about $5 \mathrm{~mm}$. The top of the hollowed-out part was closed by a $5 \mathrm{~mm}$ thick lid made of the same material and machined with an opening of $10 \mathrm{~mm}$ diameter allowing for the observation of the sample. A ring made of the same material (about $8 \mathrm{~mm}$ thick and $10 \mathrm{~mm}$ high) was placed around the sample so as not to degrade the thermal insulation too much.

- Design \#3 consisted in removing the ring on the Design \#2. In this case the interaction of the surrounding insulating material with the electric field was reduced but, on the counterpart, the thermal insulation was poorer.

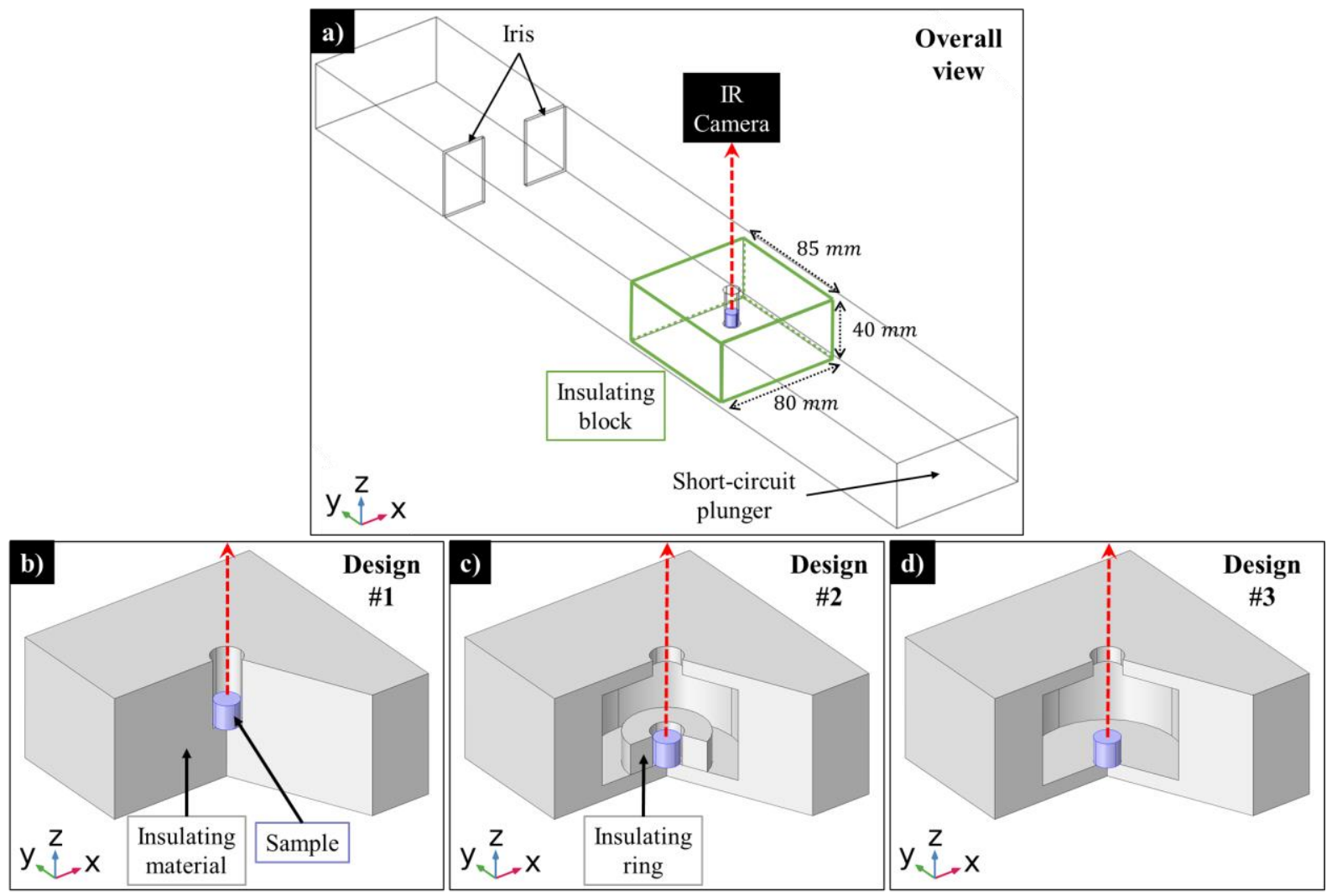

Figure 3. Schemes of the different insulation cell designs

a) overview of the positioning of the insulation block in the microwave cavity and close-up on b) Design \#1 c) Design \#2 and c) Design \#3

\subsection{Thermal cycle}

The thermal cycle was composed of a $25^{\circ} \mathrm{C} / \mathrm{min}$ heating rate followed by a $10 \mathrm{~min}$ dwell at $1500^{\circ} \mathrm{C}$. Then, microwave emission was shut down and natural cooling occurred. 


\section{Numerical simulation}

Numerical modelling was carried out with COMSOL Multiphysics® 5.4 software. Based on the finite element method, this software made it possible to simulate 3D phenomena by coupling different "physics".

\subsection{Electromagnetic calculations}

COMSOL allowed the electric field distribution in the cavity to be estimated using approximate solutions of Maxwell's equations. The $\mathrm{TE}_{10}$ type wave with forward power $P_{f}$ was introduced through the input section of the waveguide. The walls of the cavity and the short-circuit plunger were considered to be perfect conductors (infinite conductivity). Based on the distribution of the electric field, the dissipated electromagnetic power was calculated at each point of the different solid domains that constitute the sintering cell (insulator and sample), according to Equation 1.

\subsection{Thermal calculations}

The heat transfers in the domains were described by the classical heat equation:

$$
Q=\rho C_{p} \frac{\delta T}{\delta t}+\rho C_{p} u \cdot \nabla T-\nabla \cdot(k \nabla T)
$$

The heat source $Q$ takes the $Q_{e}$ value determined by the results of the electromagnetic calculations (Equation 1). Only the elements of the sintering cell (insulation, air between the insulating box and the sample) and their exchanges with the outside were included in the thermal calculations. The air outside the sintering cell and the walls of the cavity were not included. The external surfaces of the insulating box were subject to the conditions of radiative and convective exchange limits verifying:

$$
\begin{gathered}
q_{c o n v}=h\left(T_{a m b}-T\right) \\
q_{r a d}=e \sigma_{S B}\left(T_{a m b}{ }^{4}-T^{4}\right)
\end{gathered}
$$

where $h$ is the convection heat exchange coefficient, $T_{a m b}$ is the ambient temperature (boundary conditions), $e$ is the surface emissivity, and $\sigma_{S B}$ is the Stefan-Boltzmann constant. Heat transfers within the sintering cell occurred by conduction and radiation. The radiative exchanges from surface to surface within the cell were calculated by 
considering at each point the emitted radiation $\left(e \sigma_{S B} T^{4}\right)$ and the received radiation $(G)$. The radiative heat flux was the difference between absorbed and emitted radiation:

$$
q_{\text {rad }}=e\left(G-\sigma_{S B} T^{4}\right)
$$

The convective exchanges resulting from air flow were considered negligible compared to the radiative exchanges in the sintering cell. Besides, their integration would have led to numerical convergence problems and long computation times.

\subsection{Deformation calculations}

The sample subjected to the temperature field provided by the previous thermal calculation deforms under the action of the sintering. It is important to evaluate this deformation, on the one hand, because the geometry of the sample influences the distribution of the electric field and the heat transfers and, on the other hand, because the electromagnetic and thermal parameters are strongly dependent on the density of the material, which varies as its volume changes. Instead of running a full mechanical calculation, we used a simplified approach as the one proposed in [24]. The sintering material was assumed to obey a fictitious isotropic, linear thermo-elastic law approximating the sintering deformations during a test with a given heating rate. The pseudo-coefficient of thermal expansion $\alpha^{*}$ of this law was deduced from a shrinkage curve obtained by ThermoMechanical Analysis (TMA) with the relation:

$$
\Delta L / L_{0}=\alpha^{*}\left(T-T_{0}\right)
$$

where $\Delta L / L_{0}$ is the shrinkage measured at temperature $T$ and $T_{0}$ is room temperature. Between room temperature and the temperature at which sintering starts, the measured $\alpha^{*}$ is the coefficient of thermal expansion of the material. Above this temperature, this coefficient value decreases, to become negative, as a consequence of the shrinkage induced by sintering. It can be noted that this approach does not describe the shrinkage during a temperature dwell. As elastic parameters, the Young's modulus and the Poisson's ratio of alumina or zirconia at room temperature have been used. For a better description of stresses and induced strains, viscous effects at high temperature should have been taken into account by using a temperature-dependent pseudo Young's modulus, as explained in [24]. 
The relative density, $\rho_{r}$, was calculated at each moment and at each point of the sample by integrating the equation:

$$
\frac{1}{\rho_{r}} \times \frac{d \rho_{r}}{d t}=-D_{x x}-D_{y y}-D_{z z}
$$

where $D_{i j}$ corresponds to the $i j$ component of strain rate tensor. At $t=0, \rho_{r}$ is $\rho_{r}^{i n i}$ defined by the user. This density is relative to the theoretical density at room temperature, because the deformations induced by $\alpha^{*}$ include sintering shrinkage and thermal expansion. In order to obtain the relative density at the current temperature, it is necessary to subtract the contribution of thermal expansion. The calculation of the density was then corrected, taking into account an isotropic thermal expansion, as follows:

$$
\rho_{r}^{\text {corr }}=\rho_{r} \times\left(1+\alpha\left(T-T_{0}\right)\right)^{3}
$$

where $\alpha$ is the coefficient of thermal expansion of the material, which has been calculated using the cooling part of a TMA curve.

The variation of the permittivity as a function of the relative density was calculated at each point in the sample using Lichtenecker's formula validated by Simpkin (2010) [25]:

$$
\epsilon_{m i x}^{*}=\prod_{n=1}^{N} \epsilon_{n}^{* \alpha_{n}}
$$

where $\epsilon_{m i x}^{*}$ is the effective permittivity of the mixture, $\epsilon_{n}^{*}$ is the permittivity of component $n$, and $\alpha_{n}$ is the volume fraction of component $n$. The material was considered to be a mixture of dense ceramic of permittivity $\epsilon_{\text {mat }}^{*}$ and pores of permittivity $\epsilon_{\text {air }}^{*}=1$, whose permittivity is expressed as:

$$
\epsilon_{m i x}^{*}\left(T, \rho_{r}^{c o r r}\right)=\epsilon_{m a t}^{*}(T)^{\rho_{r}^{c o r r}}
$$

The variation of the thermal conductivity as function of the relative density was assumed to follow a simple law of mixture of a solid material of conductivity $k$ and pores of conductivity 0 :

$$
k\left(T, \rho_{r}^{\text {corr }}\right)=\rho_{r}^{\text {corr }} \times k\left(T, \rho_{r}=1\right)
$$




\subsection{Thermal cycle regulation}

As in the experiments, a PID loop calculated the displacement of the short-circuit plunger that allowed a prescribed variation of the maximum temperature in the upper surface of the sample. The displacement of the plunger resulted in a variation of the volume of the cavity, which required a deformation of part of the meshing of the air domain, as shown in Figure 4. In this way, the electric field distribution in the cavity was calculated considering its current geometry (Figure 4).

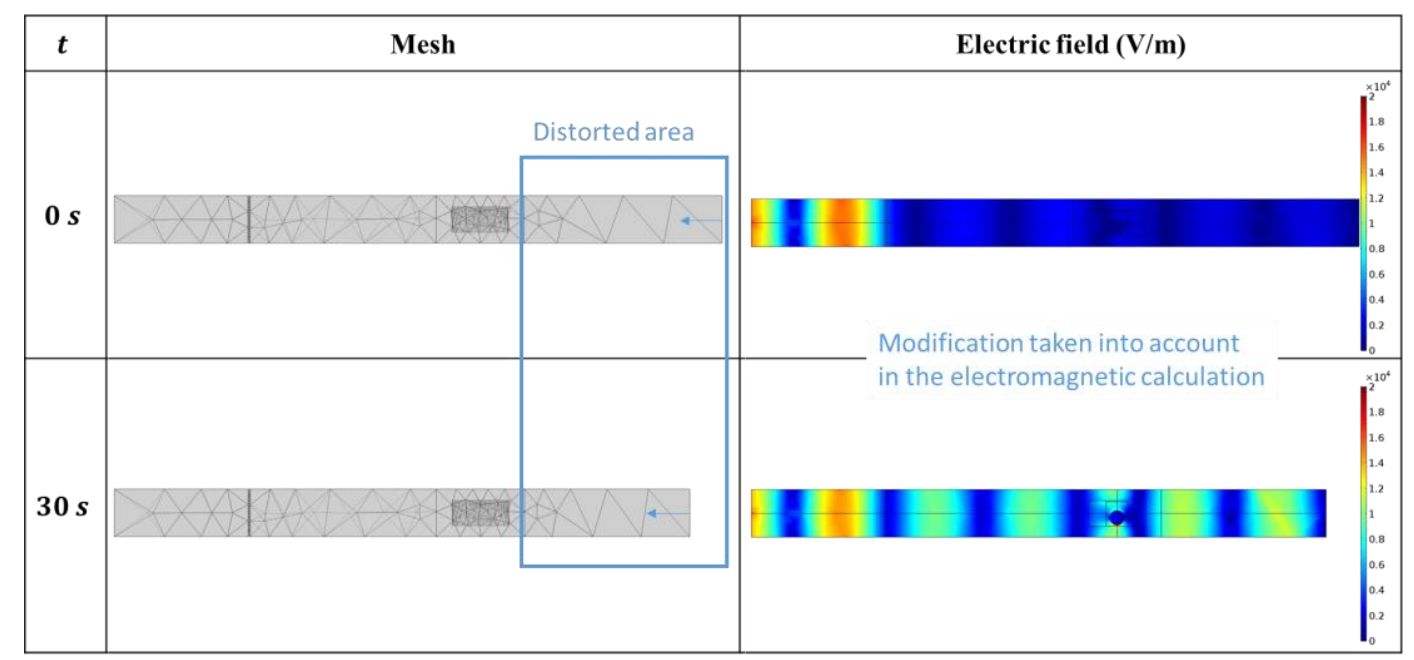

Figure 4. Illustration of the plunger displacement resulting in meshing deformation and in the increase of the electric field intensity in the cavity by the displacement of the short-circuit plunger, e.g., at $t=0$ and $30 \mathrm{~s}$ for a plunger speed of $1 \mathrm{~mm} / \mathrm{s}$

\subsection{Material data}

Table 1 provides the values of the parameters used in the numerical simulation. 
Table 1: Alumina data

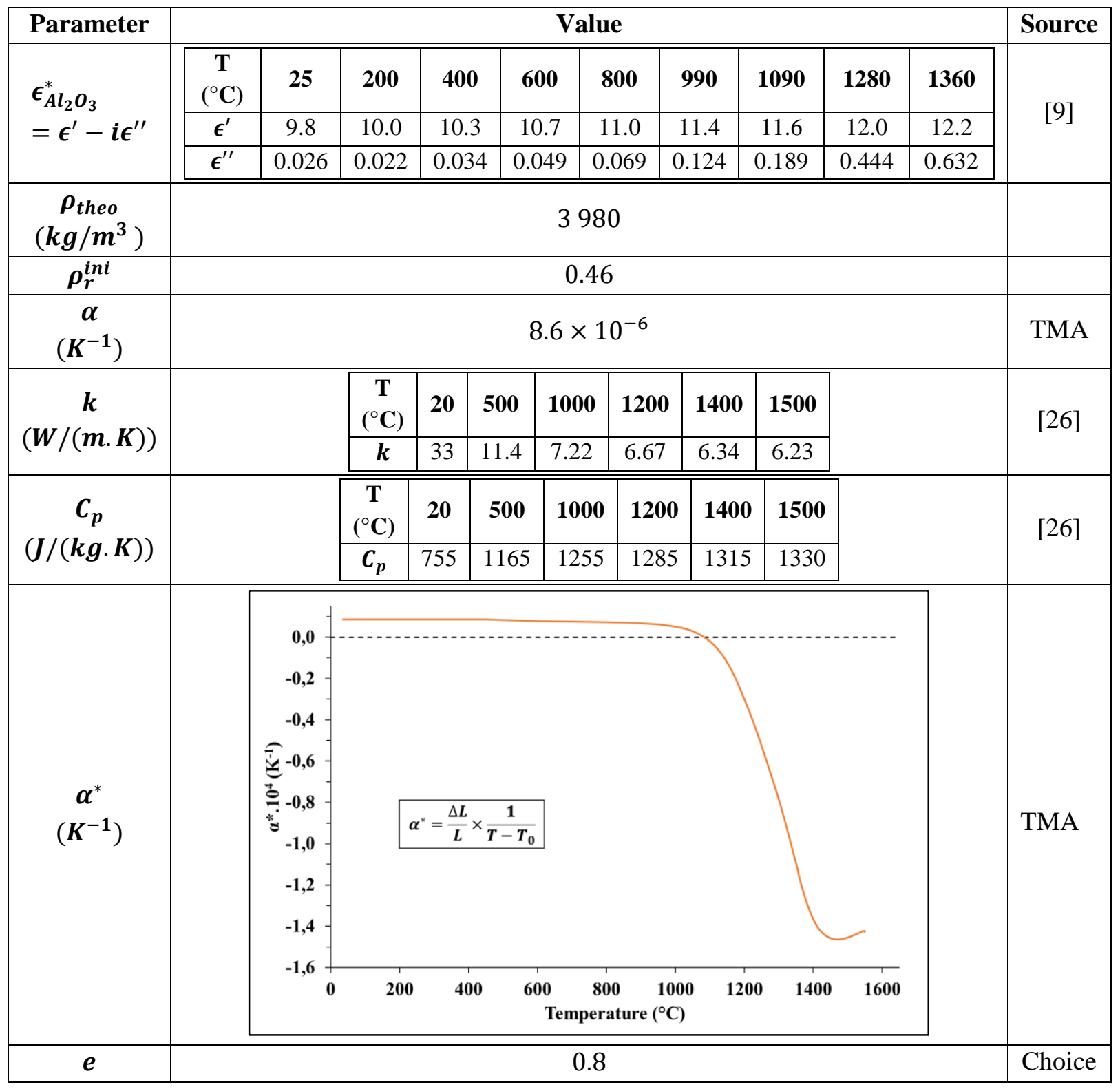


Table 2: Zirconia data

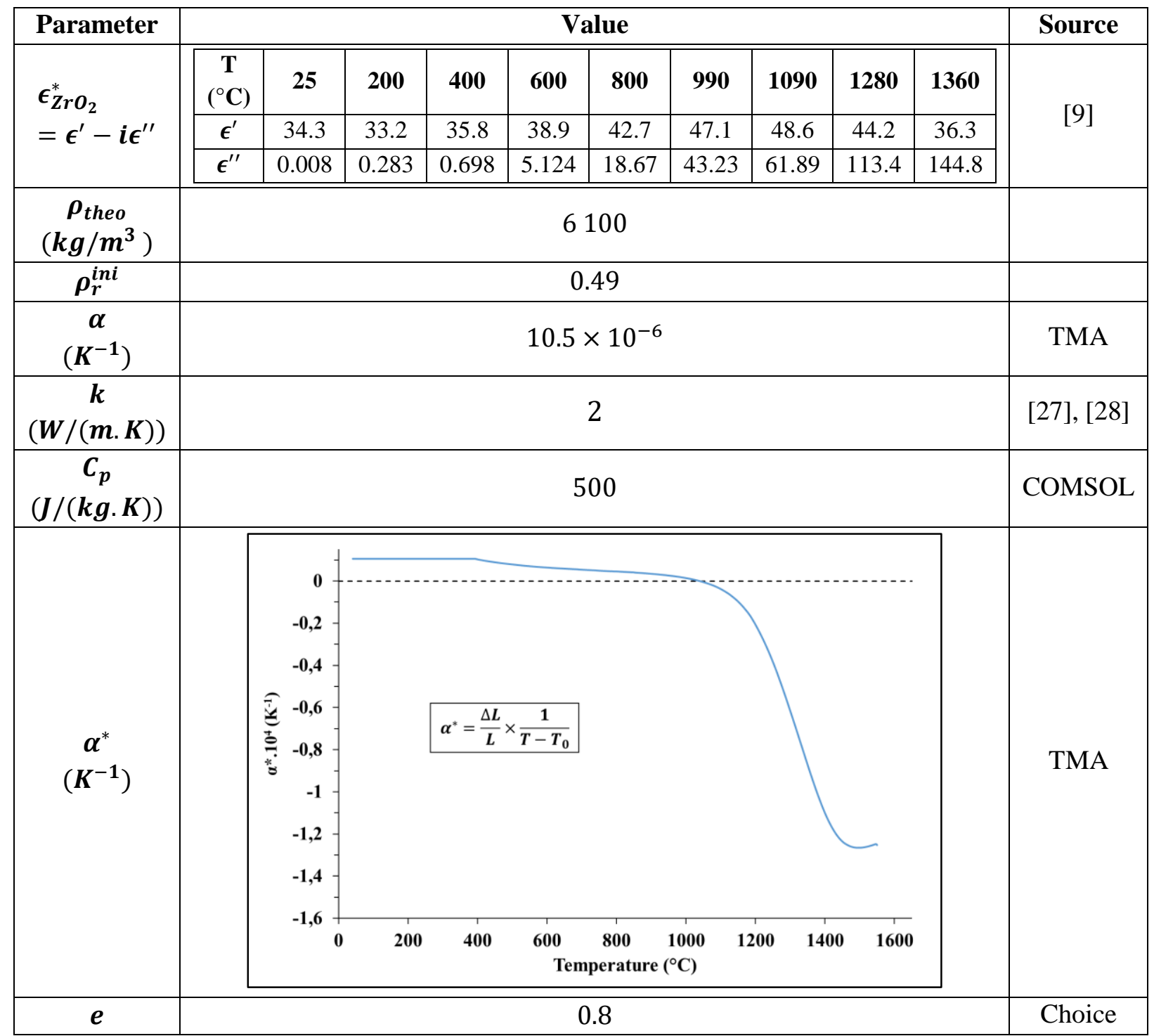


Table 3: Insulating material data

\begin{tabular}{|c|c|c|c|c|c|c|c|c|c|c|}
\hline Parameter & \multicolumn{9}{|c|}{ Value } & Source \\
\hline \multirow{3}{*}{$\begin{array}{l}\epsilon_{i s o}^{*} \\
=\epsilon^{\prime}-i \epsilon^{\prime \prime}\end{array}$} & $\begin{array}{c}\mathbf{T} \\
\left({ }^{\circ} \mathbf{C}\right)\end{array}$ & 25 & 200 & 400 & 600 & 800 & 1090 & 1280 & 1360 & \\
\hline & $\epsilon^{\prime}$ & 1.44 & 1.45 & 1.45 & 1.46 & 1.47 & 1.48 & 1.49 & 1.49 & \\
\hline & $\epsilon^{\prime \prime}$ & 0.0006 & 0.0005 & 0.0008 & 0.0011 & 0.0015 & 0.0062 & 0.0131 & 0.0131 & \\
\hline $\begin{array}{c}\rho_{\text {theo }} \\
\left(\boldsymbol{k g} / \boldsymbol{m}^{3}\right)\end{array}$ & \multicolumn{9}{|c|}{400} & $\begin{array}{c}\text { Commercial } \\
\text { data }\end{array}$ \\
\hline $\begin{array}{c}\boldsymbol{k} \\
(\boldsymbol{W} /(\boldsymbol{m} \cdot \boldsymbol{K}))\end{array}$ & \multicolumn{9}{|c|}{0.34} & $\begin{array}{c}\text { Commercial } \\
\text { data }\end{array}$ \\
\hline $\begin{array}{c}\boldsymbol{C}_{\boldsymbol{p}} \\
(\boldsymbol{J} /(\boldsymbol{k g} \cdot \boldsymbol{K}))\end{array}$ & \multicolumn{9}{|c|}{1000} & $\begin{array}{c}\text { Commercial } \\
\text { data }\end{array}$ \\
\hline$e$ & \multicolumn{9}{|c|}{0.95} & Choice \\
\hline
\end{tabular}

\section{Microwave sintering of alumina}

\subsection{Design \#1}

The first tests carried out with this insulating cell design were successful in terms of heating cycle control throughout the entire sintering cycle. The total dissipated power ranged between 200 and $300 \mathrm{~W}$ during the tests, which is quite similar to the experimental results of the tests carried out by Croquesel et al. [10]. Nevertheless, after several uses of the same insulating cell, the characteristic sound of plasma was often heard. By carefully observing the insulating cell after the heating cycle, it was clearly seen that cracks were formed in the cell. Molten areas inside the insulating cell can even be seen, as shown in Figure 5. 


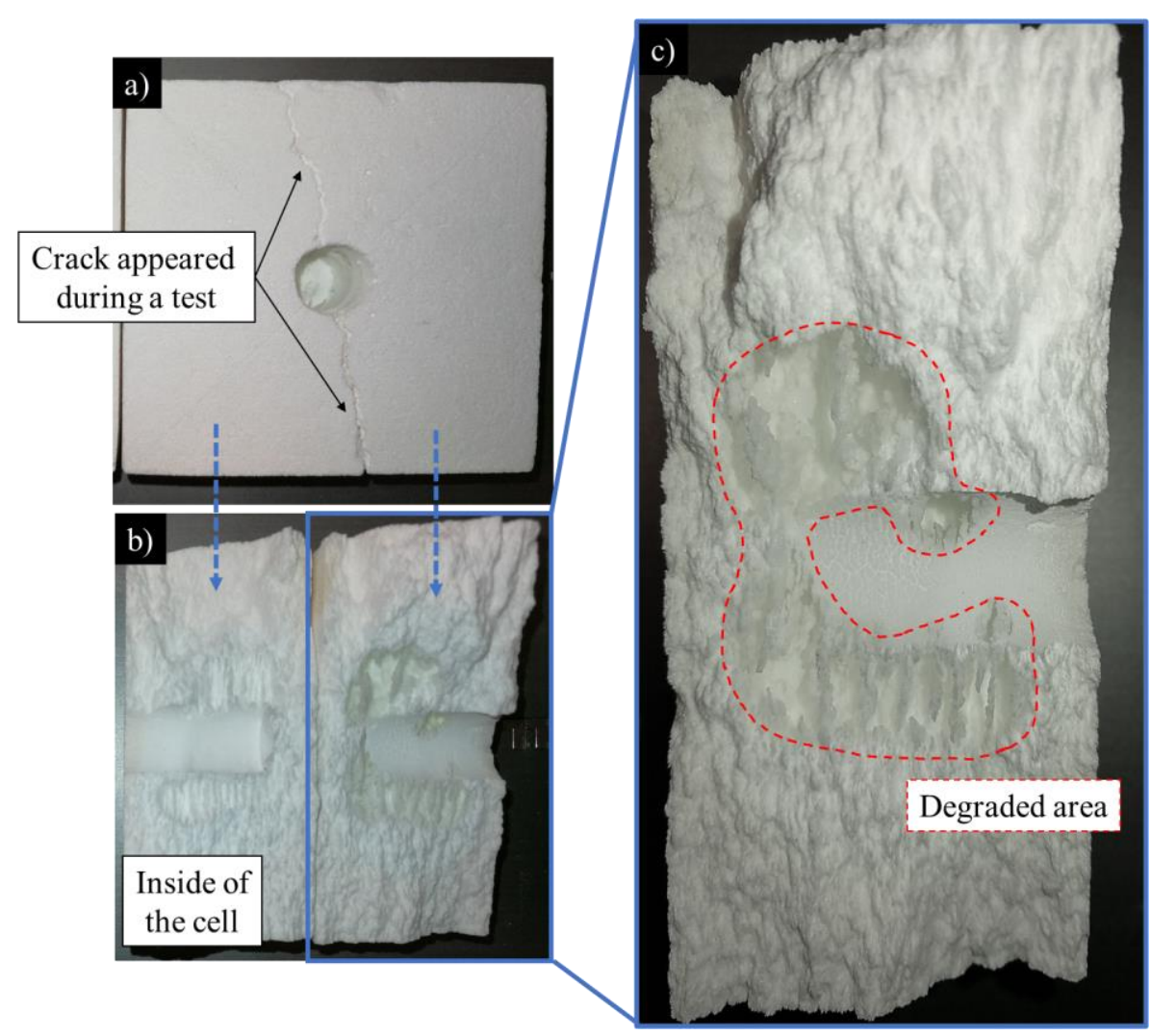

Figure 5. Pictures of an insulating cell, with Design \#1, degraded during a microwave test a) top view of the cell where a crack was observed $b$ ) internal view of the cell, via its opening following the crack and c) zoom on one of the axial sections of the cell revealing a degraded area of the insulation.

The overheating of the insulation material, which led to local melting, indicates that temperature has exceeded $1800^{\circ} \mathrm{C}$. This overheating was concomitant with the formation of plasma. A fine observation of the cell proved that it was not heated by heat transfer from the sample but by an internal heat source, which was logically created by microwave coupling.

The results of the numerical simulation of a direct microwave heating test in this configuration are presented in Figure 6. Figure 6a is composed of two plots: (i) the variation, of the maximum temperatures at the surface of the sample $\left(T_{\max }^{\text {surfsamp }}\right)$, in the volume of the sample $\left(T_{\max }^{\text {samp }}\right)$, in the volume of the insulation cell $\left(T_{\max }^{\text {insu }}\right)$ and (ii) the power dissipated in the sample $\left(P_{d}^{s a m p}\right)$, dissipated in the insulation $\left(P_{d}^{i n s u}\right)$ and total $\left(P_{d}^{\text {tot }}\right)$ as functions of time. Figure $6 \mathrm{~b}$ shows the temperature field in a cross section of the insulation cell and in a cross section of the sample at two different times. 

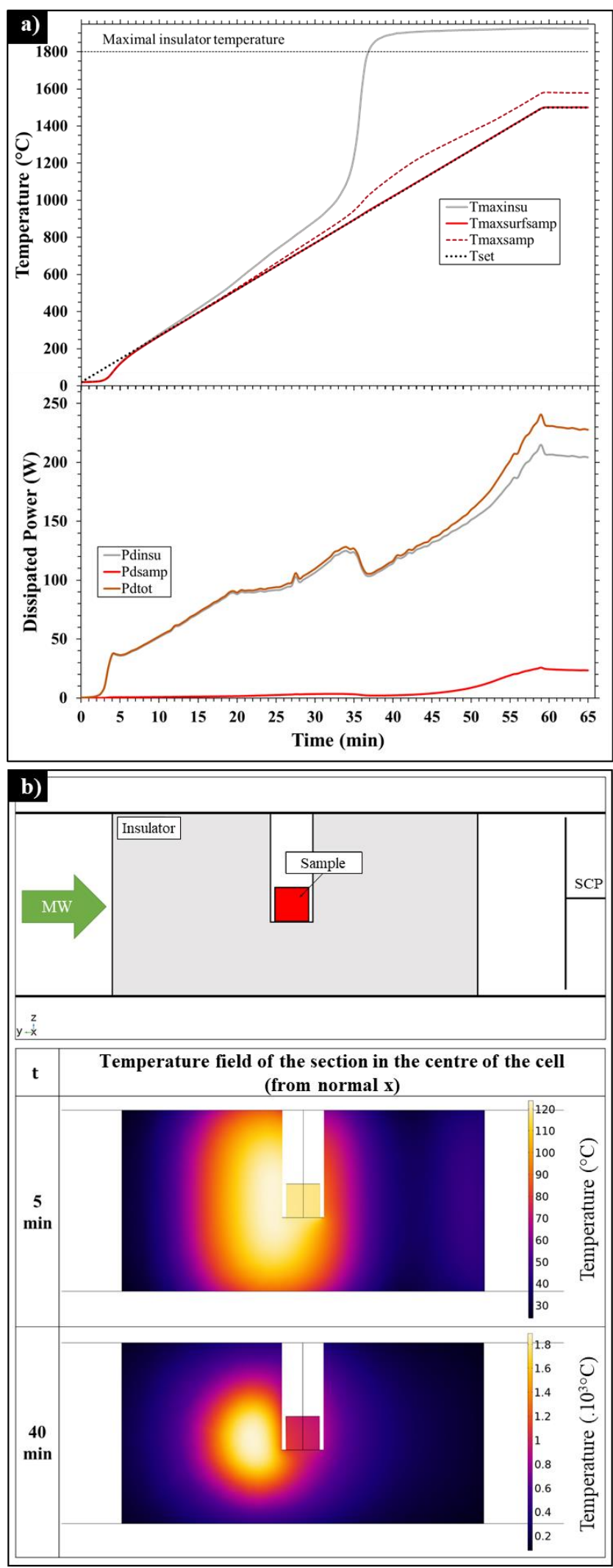

Figure 6. FEM simulations of a direct microwave heating test of an alumina sample with Design \#1 a) variation of temperatures and dissipated powers and b) diagram of the view of the section in the centre of the cell and temperature field in the insulation and sample, at different times 
According to the simulation, although the permittivity $\epsilon^{\prime \prime}$ of the insulating material is much lower than that of the sample, the insulating cell dissipated most of the microwave energy throughout the test due to a much larger volume. However, its low thermal conductivity limited its ability to dissipate the generated heat. This resulted, early in the test, in the appearance of a zone into the insulation material where the temperature was higher than the one in the sample. This local high temperature in the cell favoured its coupling capability and resulted in a localized thermal runaway (hot spot, Figure 6b). This runaway can even lead to a temperature above the melting point of the insulation and causes its premature degradation, as experimentally observed. These results show that the insulation box did not behave like a perfect microwave transparent material, even though it has a much lower $\epsilon^{\prime \prime}$ than the one sample, i.e., of alumina. The need to apply a strong electric field (Equation 1) inevitably promoted the absorption of low $\epsilon^{\prime \prime}$ materials including the insulating material.

\subsection{Design \#2}

Figure 7 results from a test carried out with Design \#2. The applicator length

$\left(L_{\text {appli }}\right)$, the maximum temperature at the top surface of the sample $\left(T_{\max }^{\text {surfsamp }}\right)$, the set temperature $\left(T_{\text {set }}\right)$ and the total dissipated power $\left(P_{d}^{\text {tot }}\right)$ are plotted versus time. In addition, thermal images taken by the IR camera during the test are presented at different times. Although this configuration allowed a well-control thermal cycle while achieving a final density of almost $96 \%$ for the sintered part, the images taken by the thermal camera show that very early in the cycle, the sample environment was hotter than the sample itself. The total dissipated power varied from 200 to $300 \mathrm{~W}$, very similarly to the previous situation. 

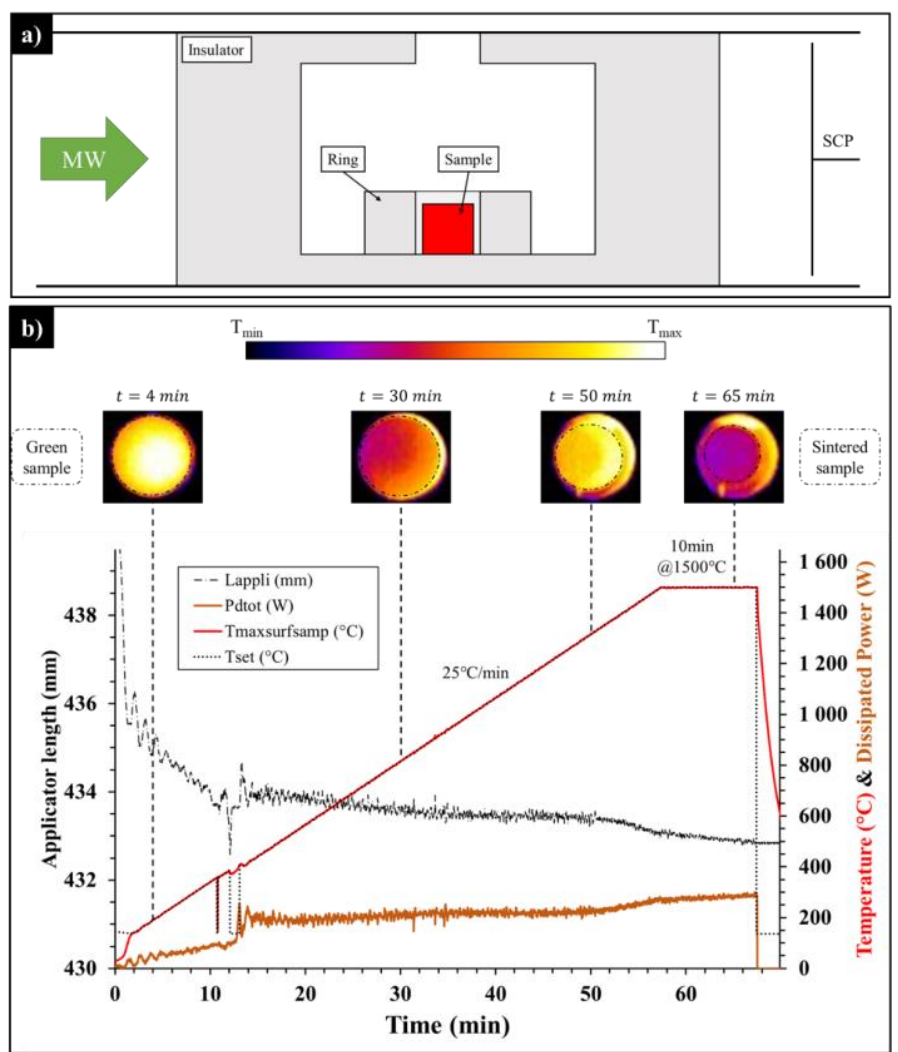

Figure 7. a) Scheme of Design \#2 b) Sintering cycle of an alumina cylinder in insulating cell with Design \#2, in automated 2,45 GHz resonant cavity

Thus, with Design \#2, the heating mode appears to be indirect, or at best hybrid, as the insulating ring apparently behaved like a susceptor. However, this configuration had a practical advantage compared to the previous one. The part of the insulating material that is likely to deteriorate, i.e., the ring, is an easily replaceable component. In a final attempt to limit the coupling of the insulating material, a sintering test was carried out without such a ring.

\subsection{Design \#3}

This design has first be modelled, as seen in Figure 8. Figure 8a is composed of two plots: (i) the variation of the maximum temperatures at the surface of the sample $\left(T_{\max }^{\text {surfsamp }}\right)$, in the volume of the sample $\left(T_{\max }^{\text {samp }}\right)$, in the volume of the insulation cell $\left(T_{m a x}^{i n s u}\right)$ and (ii) the power dissipated in the sample $\left(P_{d}^{\text {samp }}\right)$, dissipated in the insulation $\left(P_{d}^{i n s u}\right)$ and total $\left(P_{d}^{\text {tot }}\right)$ vs time. Figure $8 \mathrm{~b}$ shows the temperature field in a cross section of the insulation cell and in a cross section of the sample at different times. 

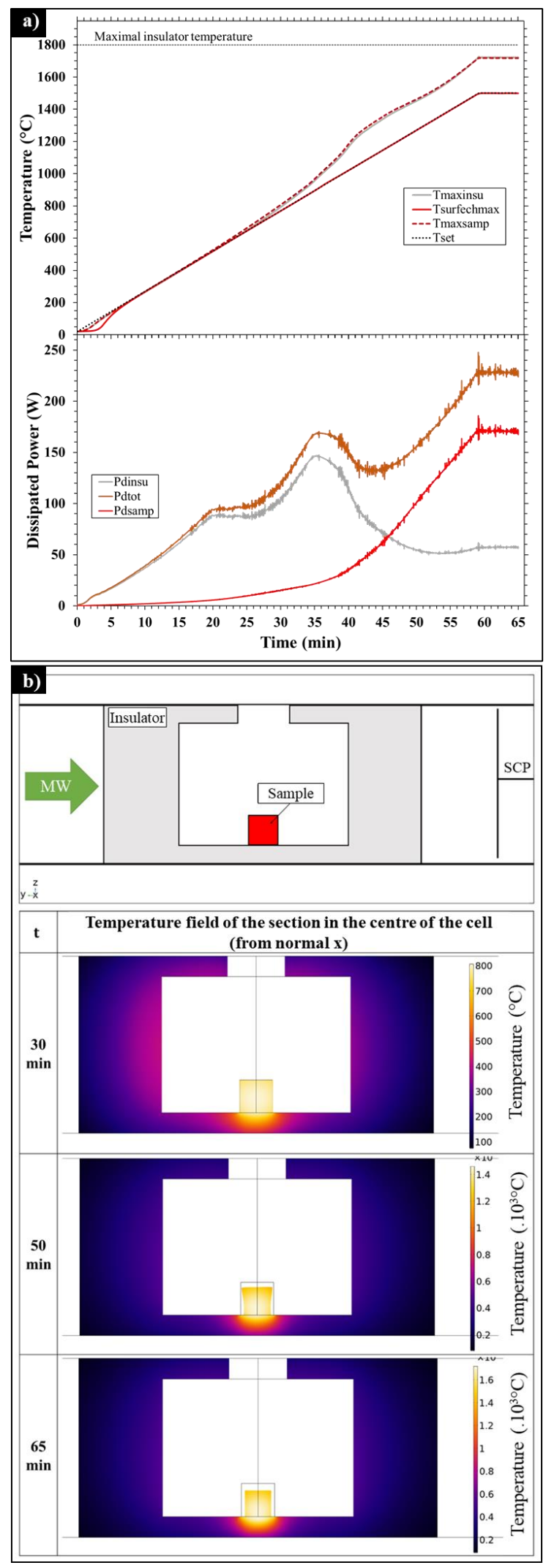

Figure 8. FEM simulations of a direct microwave heating test of an alumina sample with Design \#3 a) variation of the temperatures and of the dissipated powers of the insulation material and the sample b) view of the section in the centre of the cell and temperature field in the insulation and sample, at three different times 
Although the total dissipated power is about the same as in the test with Design \#1 (Figure 6), the proportion of power dissipated in the sample is much higher. At the end of the test, most of the power has dissipated into the sample. No overheating of the insulation is observed. This configuration thus favours the coupling of the sample over the coupling of the insulation. However, the power dissipated in the sample is much higher, up to 170 $\mathrm{W}$, with this configuration than with the Design \#1, below $25 \mathrm{~W}$. This is because the thermal radiation losses of the sample are much higher with this cell, whose walls are cooler. The cell is therefore less efficient in terms of thermal insulation. This results in a stronger thermal gradient in the sample than the one found with the initial cell. The base of the sample in contact with the cell is much better insulated than its other surfaces, and particularly better than the upper surface of the sample, which faces the hole drilled for temperature measurement.

An experiment with Design \#3 was also carried out (Figure 9). A sintered sample was obtained with a relative density of $98.7 \%$. Experimentally, the dissipated power was very high $(\sim 800 \mathrm{~W})$ compared to the value predicted by modelling $(250 \mathrm{~W})$ and a significant thermal radiation coming from the insulation cell was observed. This very high dissipated power also conducted to the degradation of the insulating material, as already seen (Figure 5).

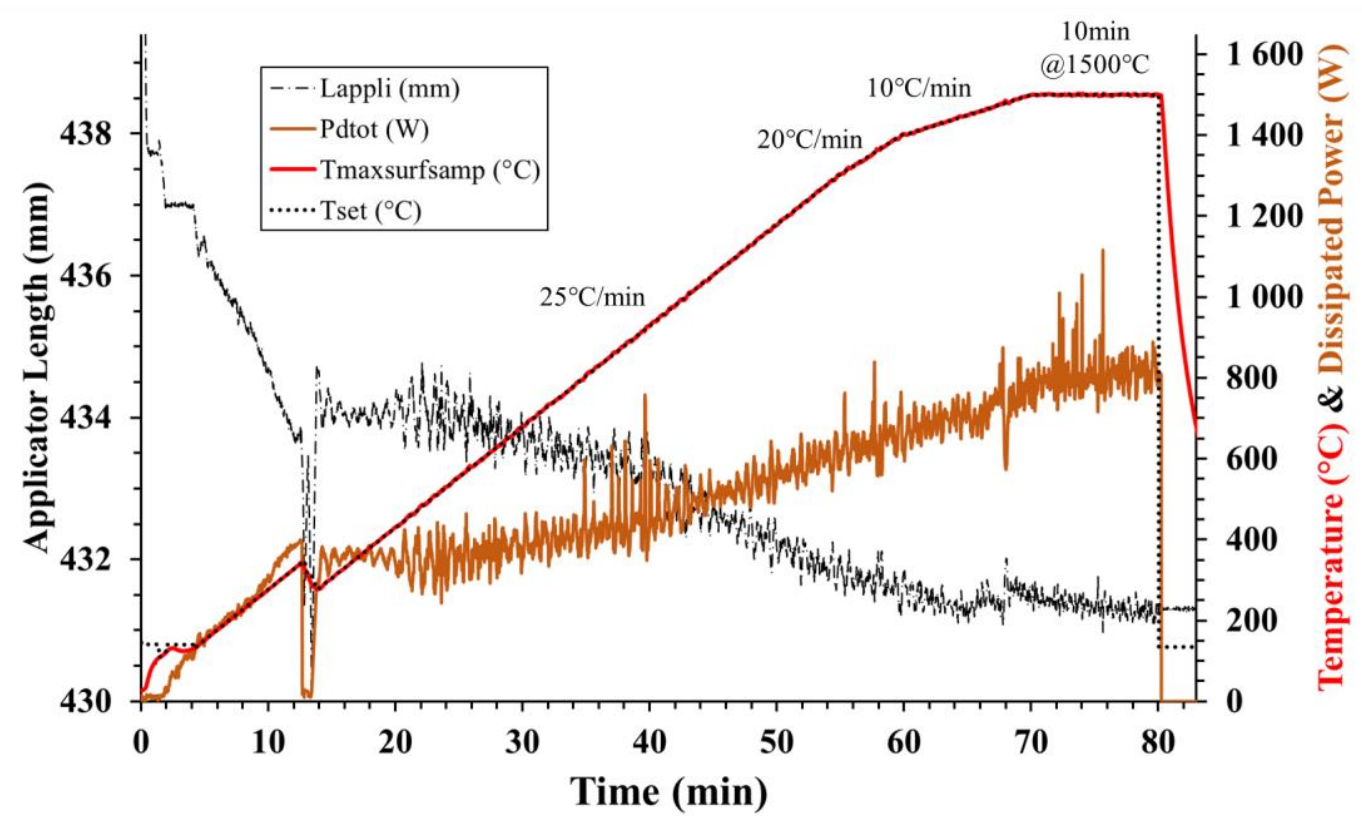

Figure 9. Sintering cycle of an alumina cylinder with Design \#3, in automated 2,45 GHz resonant cavity 
The following reasons may explain the degradation of the insulating material:

(i) The volume of the sample being small, its capacity to couple with microwave is very low and, as no surrounding insulating material is used, the convective thermal losses cannot be neglected, as it is in the simulation.

(ii) Because of (i), following the programmed thermal cycle required increasing the microwave power and the insulating material no longer coupled. However, the microwave power was very high at that time and hot spots may be generated.

\subsection{Summary}

None of the tested assemblies provided a satisfactory direct heating of alumina samples. When the cell provided effective thermal insulation of the sample (Design \#1 and \#2), the presence of the insulating material in an area of high electric field intensity resulted in its strong coupling with the microwaves, which led to its degradation. When the interaction of the cell with the field was greatly reduced by limiting the presence of the insulating material in this area (Design \#3), thermal losses from the sample were favoured, hindering its heating.

It is concluded that direct microwave heating of alumina for sintering is very challenging, mainly because of the low microwave coupling properties of this material. It is next interesting to investigate a material which exhibits much higher dielectric losses, as yttria stabilised zirconia.

\section{Microwave sintering of zirconia}

\subsection{Experimental test with Design \#3}

The sintering test of yttria doped zirconia were performed in an insulating cell with Design \#3. This geometry is the best one to reduce the risk of energy absorption by the insulating box. The experimental results are shown in Figure 10. The applicator length, the total dissipated power and the maximum, minimum and average temperature at the upper surface of the specimen are plotted vs time. From room temperature to $500^{\circ} \mathrm{C}$, the maximum temperature followed the target cycle with less than $30 \mathrm{~W}$ of dissipated power. From 500 to $700^{\circ} \mathrm{C}$ the temperature did not follow the programmed cycle and the system was unstable. The system actually tried to adjust the applicator length to reduce the field intensity in response to the strong acceleration of the sample absorption. During 
the test, the automatic regulation was suspended (as proved by the discontinuities of $T_{\text {set }}$ in Figure 10a) to avoid a thermal runaway. Despite changes in the PID values, the temperature control could not be satisfactorily achieved. In addition, a thermal gradient was observed in the sample surface (which was hotter in the centre than in its periphery). From 700 to $1000^{\circ} \mathrm{C}$, the temperature regulation became satisfactory but the thermal gradient remained and even increased. The difference between the maximum and minimum temperatures recorded by the thermal imaging camera in the surface of the sample exceeded $300^{\circ} \mathrm{C}$, which is extremely high. From $1000^{\circ} \mathrm{C}$ to $\sim 1350^{\circ} \mathrm{C}$ this temperature gradient disappeared and the system was under control. However, above $\sim 1350^{\circ} \mathrm{C}$ a plasma systematically formed, which stopped the heating, and the degradation of the insulating cell in the vicinity of the sample was most often observed after cooling. 

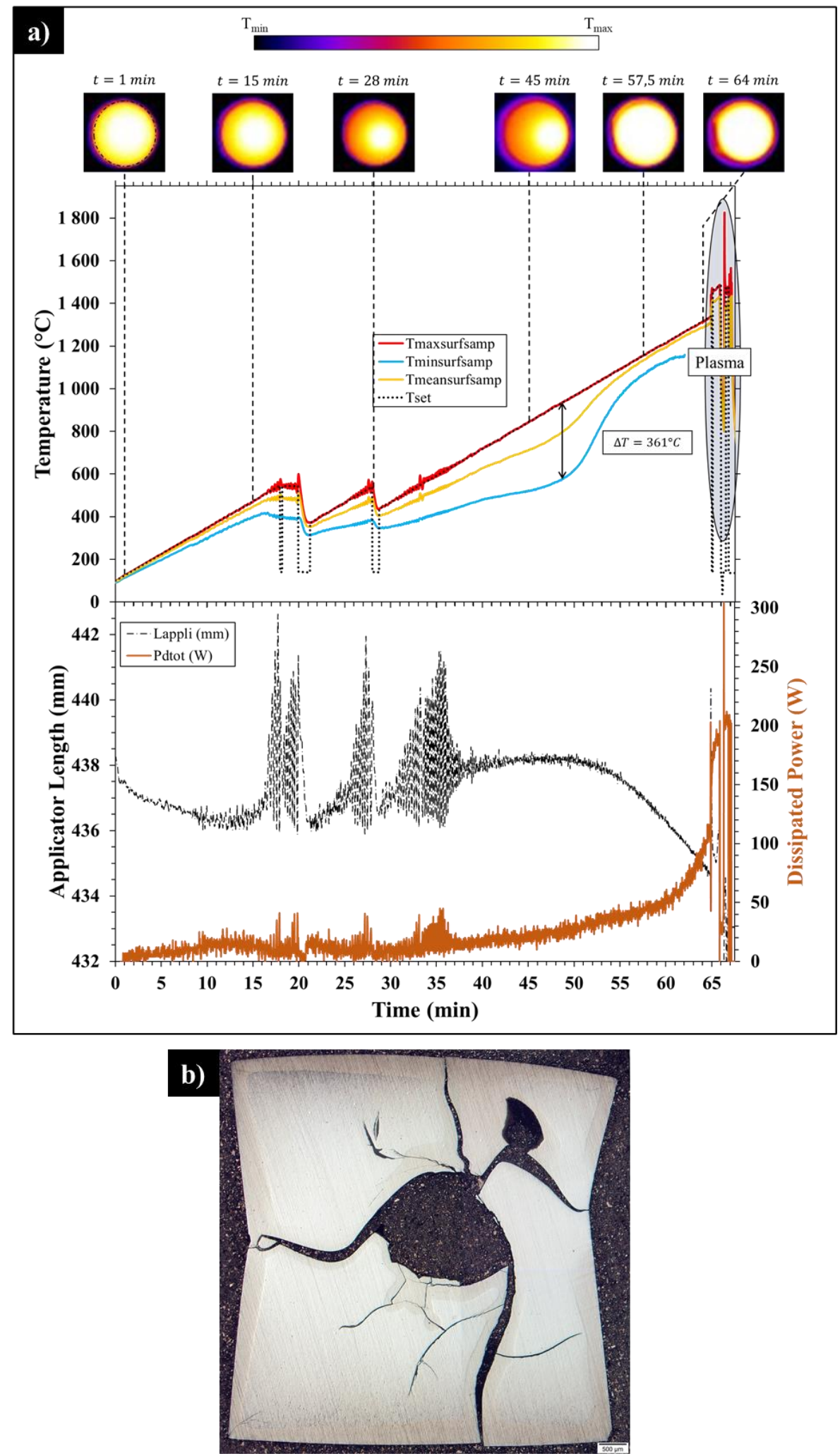

Figure 10. a) Direct sintering test of an yttria doped zirconia sample: temperatures of the upper surface of the specimen, applicator length and dissipated power as a function of time and b) axial section of an yttria doped zirconia cylinder observed by optical microscopy after a direct microwave sintering test. The central part of the specimen separated from the rest of the part during cutting. 
It is then clear that this direct heating configuration did not allow a well-controlled heating of zirconia especially in the $500-700^{\circ} \mathrm{C}$ temperature range. In addition, a high thermal gradient developed and after $1300^{\circ} \mathrm{C}$, plasma and degradation of the thermal insulation material appeared. As expected, samples heated with this process exhibit very heterogeneous deformation, with a core significantly denser than the rest of the sample; cracks can be seen as well. As an example, Figure 10b shows the axial section of an yttria doped zirconia cylinder observed by optical microscopy after a direct microwave sintering test.

\subsection{Numerical simulation}

The numerical calculation of this test (Figure 11) showed the same trends as those observed experimentally and they provided additional information. Figure 11a includes three graphs. The first one shows the maximum temperatures in the surface of the sample in the sample and in the insulation. In the second one, the variations of the applicator length and the powers dissipated in the sample, in the insulation and total are plotted. The third graph shows the variation of the mean intensity of the electric field in the sample and its environment, delimited by a ball of $10 \mathrm{~mm}$ in diameter, composed by the air and the insulating material. It is possible to divide the progress of zirconia coupling into 4 stages, marked in Figure 11a:

- Stage 1 corresponds to the start of the heating cycle. The low value of $\epsilon^{\prime \prime}$ of zirconia requires the application of a strong electrical field intensity in order to initiate its heating. This promotes energy dissipation in the insulating material, which, however, remains relatively low $(<25 \mathrm{~W})$.

- Stage 2 corresponds to the increase of $\epsilon^{\prime \prime}$ of zirconia allowing it to become more dissipative. As the coupling capacity of the sample increases, the intensity of the electric field required to heat the sample decreases (Equation 1). The reduction of the electric field intensity is ensured by the displacement of the short-circuit plunger (increasing the applicator length). The proportion of power dissipated in the insulation material is therefore reduced and quickly becomes negligible at the end of stage 2. Nevertheless, during this stage, the control system must be sufficiently responsive in order to maintain the heating rate and avoid a thermal runaway. Our experimental device does not seem to be suitable, as it does not allow for both rapid and fine adjustment of the applicator length. 
- During stage 3, it is necessary to increase the energy dissipation in the sample, and therefore the intensity of the electric field, in order to continue to follow the temperature set point. Then, the applicator length decreases so that the system is closer to the resonance condition.

- In stage 4, the behaviour of zirconia changes again. Despite the increase in the electric field strength in the cavity, a decrease in the electric field in the sample is observed. The sample becomes microwave reflective. A strong increase in the electric field in the cavity is thus required, which promotes the coupling of the insulating material, resulting in an acceleration of the heating of the cell underneath the sample.

At $\mathrm{t}=54.7$ min (marked by the black dotted vertical line in the graphs of Figure 11a), the temperature of the insulation under the sample exceeds its limit temperature of $1800^{\circ} \mathrm{C}$ and it continues to rise very rapidly (up to over $4000^{\circ} \mathrm{C}$ at the beginning of the dwell). After this event, the simulation results deviate greatly from the experimental observation, as the simulation does not take into account the melting of materials. However, these results remain consistent with experimental observations where plasma creation and degradation of the insulating material underneath the sample were observed. 


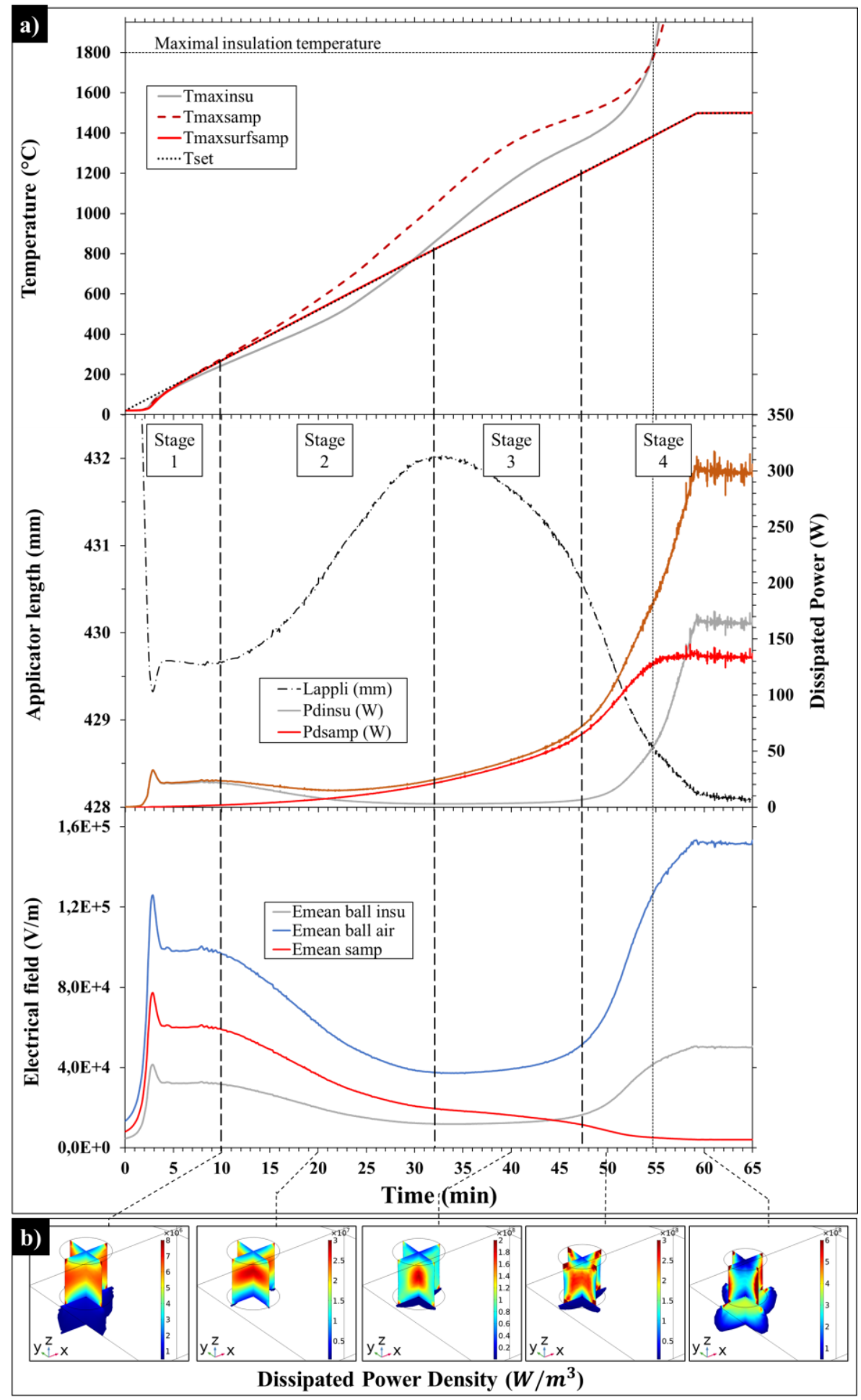

Figure 11. FEM simulations of a direct microwave heating test of an yttria doped zirconia sample with Design \#3 a) variation of the temperatures and of the dissipated powers of the insulation material and the sample; and variation of the mean electrical field intensity in the sample and the air and insulating material surrounding the sample b) evolution of the dissipated power density distribution in the sample 
Figure $11 \mathrm{~b}$ shows the distribution of the power dissipated in the sample during the cycle. Between $t=20 \mathrm{~min}$ and $t=40 \mathrm{~min}$, a concentration of the dissipated energy in the centre of the sample is observed, favouring the appearance of a thermal gradient between the hotter core of the sample and its colder walls. This is explained by the rapid increase in $\epsilon^{\prime \prime}$ of the zirconia with increasing temperature. Naturally, direct heating favours the creation of such a temperature gradient. In the case of zirconia, even a small thermal gradient results in a significant gradient of $\epsilon^{\prime \prime}$. This phenomenon is then accentuated by zirconia low thermal conductivity that limits its ability to transmit heat from its core to its surface. The core gets hotter and hotter and therefore more and more dissipative, favouring its localised heating and the appearance of a hot spot. The strong thermal gradient in the sample persists up to high temperature. This explains the heterogeneous shrinkage observed during experiments (Figure 10b). This thermal gradient is naturally favoured by the low thermal insulation of the cell, which can promote heat loss on the surface of the sample. Nevertheless, even with better insulation, this behaviour can only be favoured by applying high heating rates or processing larger components.

\section{Conclusion}

In this work, direct microwave heating tests with automatic temperature control have been performed with alumina and zirconia samples and compared with numerical simulations including electromagnetic, thermal and densification coupling. It has been shown that an insulating material, even with a very low microwave coupling capacity, can become an absorbent medium when a sufficiently strong electric field is applied to it. As a result, an insulating cell can act as a susceptor for samples with low coupling capacity such as pure alumina. In order to reduce the interaction of the insulating material with the field, different cell geometries have been considered, especially by limiting the amount of insulating material around the sample. Nevertheless, this method inevitably degrades the thermal insulation capacity of the system, which favours the appearance of thermal gradients and the application of higher field strengths.

Zirconia, on the other hand, shows a rapid evolution of its $\epsilon^{\prime \prime}$ with temperature, changing from poorly to highly microwave absorbent and even becoming reflective at high temperatures. This rapid change in its dielectric properties, combined with very low thermal conductivity, favours the formation of hot spots and makes it extremely difficult to control its heating, even with an automated system. The loss of its coupling capacity at 
very high temperature results in the coupling of the insulating cell and the creation of plasma.

This study clearly evidences the difficulty of running effective direct microwave sintering of both alumina and zirconia. Therefore, susceptor-assisted heating appears to be the most relevant method to ensure efficient and controlled microwave sintering of these materials. Depending of the susceptor features (material, geometry, location), the heating may be perfectly indirect or hybrid, i.e., the sintering compact being partially heated by interaction with the residual electrical field. 


\section{Funding}

This work was supported by ANR \#17 CE08 0021.

\section{Declaration of interests}

The authors declare that they have no known competing financial interests or personal relationships that could have appeared to influence the work reported in this paper. 


\section{References}

[1] E. Clark, « Microwave Processing of Materials », Annual Review of Materials Science, vol. 26, $\mathrm{n}^{0}$ 1, p. 299-331, 1996.

[2] C. Zhao, J. Vleugels, C. Groffils, P. J. Luypaert, et O. Van Der Biest, « Hybrid sintering with a tubular susceptor in a cylindrical single-mode microwave furnace », Acta Materialia, vol. 48, no 14, p. 3795-3801, sept. 2000, doi: 10.1016/S1359-6454(00)00160-9.

[3] K. H. Brosnan, G. L. Messing, et D. K. Agrawal, « Microwave Sintering of Alumina at $2.45 \mathrm{GHz} »$, Journal of the American Ceramic Society, vol. 86, $\mathrm{n}^{\circ}$ 8, p. 1307-1312, 2003, doi: 10.1111/j.1151-2916.2003.tb03467.x.

[4] S. Singh, D. Gupta, V. Jain, et A. K. Sharma, « Microwave Processing of Materials and Applications in Manufacturing Industries: A Review », Materials and Manufacturing Processes, vol. 30, $\mathrm{n}^{\circ}$ 1, p. 1-29, janv. 2015, doi: 10.1080/10426914.2014.952028.

[5] H. Curto et al., « Coupling additive manufacturing and microwave sintering: A fast processing route of alumina ceramics », Journal of the European Ceramic Society, vol. 40, no 7, p. 2548-2554, juill. 2020, doi:

10.1016/j.jeurceramsoc.2019.11.009.

[6] C. Monaco, F. Prete, C. Leonelli, L. Esposito, et A. Tucci, « Microstructural study of microwave sintered zirconia for dental applications », Ceramics International, vol. 41, n⿳⺈ 1, Part B, p. 1255-1261, janv. 2015, doi: 10.1016/j.ceramint.2014.09.055.

[7] M. Arai, J. G. P. Binner, et T. E. Cross, «Comparison of Techniques for Measuring High-Temperature Microwave Complex Permittivity: Measurements on an Alumina/Zircona System », Journal of Microwave Power and Electromagnetic Energy, vol. 31, nº 1, p. 12-18, janv. 1996, doi: 10.1080/08327823.1996.11688287.

[8] N.-E. Belhadj-Tahar, A. Fourrier-Lamer, et H. de Chanterac, « Broad-band simultaneous measurement of complex permittivity and permeability using a coaxial discontinuity », IEEE Transactions on Microwave Theory and Techniques, vol. 38, nº 1, p. 1-7, janv. 1990, doi: 10.1109/22.44149.

[9] J. Batt et al., « A Parallel Measurement Programme in High Temperature Dielectric Property Measurements: An Update », déc. 1995, vol. 59, p. 243-250.

[10] J. Croquesel, D. Bouvard, J.-M. Chaix, C. P. Carry, et S. Saunier, « Development of an instrumented and automated single mode cavity for ceramic microwave sintering: Application to an alpha pure alumina powder », Materials \& Design, vol. 88, p. 98-105, déc. 2015, doi: 10.1016/j.matdes.2015.08.122.

[11] J. Croquesel, D. Bouvard, J.-M. Chaix, C. P. Carry, S. Saunier, et S. Marinel, « Direct microwave sintering of pure alumina in a single mode cavity: Grain size and phase transformation effects », Acta Materialia, vol. 116, p. 53-62, sept. 2016, doi: 10.1016/j.actamat.2016.06.027.

[12] J. Cheng, D. Agrawal, Y. Zhang, et R. Roy, « Microwave sintering of transparent alumina », Materials Letters, vol. 56, no 4, p. 587-592, oct. 2002, doi: 10.1016/S0167-577X(02)00557-8.

[13] M. Mizuno et al., « Sintering of alumina by $2.45 \mathrm{GHz}$ microwave heating », Journal of the European Ceramic Society, vol. 24, no 2, p. 387-391, janv. 2004, doi: 10.1016/S0955-2219(03)00217-6.

[14] M. Weller, R. Herzog, M. Kilo, G. Borchardt, S. Weber, et S. Scherrer, « Oxygen mobility in yttria-doped zirconia studied by internal friction, electrical 
conductivity and tracer diffusion experiments », Solid State Ionics, vol. 175, $\mathrm{n}^{\mathrm{0}} 1$, p. 409-413, nov. 2004, doi: 10.1016/j.ssi.2003.12.044.

[15] A. Goldstein, N. Travitzky, A. Singurindy, et M. Kravchik, « Direct microwave sintering of yttria-stabilized zirconia at $2 \cdot 45 \mathrm{GHz} »$, Journal of the European Ceramic Society, vol. 19, n 12, p. 2067-2072, oct. 1999, doi: 10.1016/S09552219(99)00020-5.

[16] S. Charmond, C. P. Carry, et D. Bouvard, «Densification and microstructure evolution of Y-Tetragonal Zirconia Polycrystal powder during direct and hybrid microwave sintering in a single-mode cavity », Journal of the European Ceramic Society, vol. 30, nº 6, p. 1211-1221, avr. 2010, doi: 10.1016/j.jeurceramsoc.2009.11.014.

[17] D. Feng, D. Xu, Q. Wang, et P. Liu, « Highly stretchable electromagnetic interference (EMI) shielding segregated polyurethane/carbon nanotube composites fabricated by microwave selective sintering », Journal of Materials Chemistry C, vol. 7, n 26, p. 7938-7946, 2019, doi: 10.1039/C9TC02311A.

[18] D. Hoyt, Y. Adonyi, et S. Kim, « Microwave joining - Part 1: Closed-loop controlled microwave soldering of lead telluride to copper », vol. 95, p. 141-145, avr. 2016.

[19] M. Oghbaei et O. Mirzaee, « Microwave versus conventional sintering: A review of fundamentals, advantages and applications », Journal of Alloys and Compounds, vol. 494, $\mathrm{n}^{\mathrm{o}}$ 1-2, p. 175-189, avr. 2010, doi: 10.1016/j.jallcom.2010.01.068.

[20] A. C. Metaxas et R. J. Meredith, Industrial Microwave Heating. IET, 1983.

[21] W. Bauer, A. Moldenhauer, et A. Platzer, « Emissivities of ceramic materials for for high temperature processes », in Optical Diagnostics, août 2005, vol. 5880, p. 58800W, doi: 10.1117/12.624512.

[22] D. Yajima, A. Ohnishi, et Y. Nagasaka, « Simultaneous Measurement Method of Normal Spectral Emissivity and Optical Constants at High Temperatures1 », juin 2020.

[23] B. Garcia-Baños, J. M. Catalá-Civera, F. L. Peñaranda-Foix, P. Plaza-González, et G. Llorens-Vallés, «In Situ Monitoring of Microwave Processing of Materials at High Temperatures through Dielectric Properties Measurement », Materials, vol. 9, $\mathrm{n}^{\mathrm{O}}$ 5, Art. $\mathrm{n}^{\mathrm{O}}$ 5, mai 2016, doi: 10.3390/ma9050349.

[24] F. Toussaint, D. Bouvard, P. Tenaud, et E. Di Marcello, « Experimental and numerical analysis of the deformation of ferrite segments during sintering », Journal of Materials Processing Technology, vol. 147, $\mathrm{n}^{\circ}$ 1, p. 72-78, mars 2004, doi: 10.1016/j.jmatprotec.2003.11.019.

[25] R. Simpkin, «Derivation of Lichtenecker's Logarithmic Mixture Formula From Maxwell's Equations », IEEE Transactions on Microwave Theory and Techniques, vol. 58, $\mathrm{n}^{\mathrm{o}}$ 3, p. 545-550, mars 2010, doi: 10.1109/TMTT.2010.2040406.

[26] M. Munro, «Evaluated Material Properties for a Sintered alpha-Alumina », Journal of the American Ceramic Society, vol. 80, n 8, p. 1919-1928, 1997, doi: 10.1111/j.1151-2916.1997.tb03074.x.

[27] C. Piconi et G. Maccauro, «Zirconia as a ceramic biomaterial », Biomaterials, vol. 20, nº 1, p. 1-25, janv. 1999, doi: 10.1016/S0142-9612(98)00010-6.

[28] D. R. Clarke, « Materials selection guidelines for low thermal conductivity thermal barrier coatings », Surface and Coatings Technology, vol. 163-164, p. 67-74, janv. 2003, doi: 10.1016/S0257-8972(02)00593-5. 